\title{
SEXUAL DIMORPHISM OF THE MANDIBLE IN EGYPTIAN POPULATION SAMPLE: A PANORAMIC RADIOGRAPHIC STUDY
}

\author{
Fatma M. Elgazzar*, Ghada N. El-Sarnagawy*and Abd El-Rheem R. El- Gendy** \\ Forensic Medicine and Clinical Toxicology Department, Faculty of Medicine, Tanta \\ University*, Oral medicine, periodontology, diagnosis and oral radiology Department, \\ Faculty of Dentistry, Cairo, El Azhar University**, Egypt
}

\begin{abstract}
Sex determination is a crucial issue and is usually the first step in the process of identification in forensic investigations. However, it remains a very challenging task. The aim of this study was to determine the validity of radiographic measurements, from the superior and inferior borders of the mental foramen to the lower border of the mandible (S-L and I-L), and from the medial margin of the mental foramen to the mandibular symphisis (MF -MS) on both right and left sides of the mandible, in sex determination in a sample of Egyptian population. The studied measurements were obtained digitally from high quality panoramic radiographs using imaging software. The recruited sample consisted of four hundred and thirty panoramic radiographs of patients aged 20 to 68 years with equal sex distribution. They were divided into two age groups; group 1 (from 20-50 years) and group 2 (more than 50 years). No significant difference was found in the studied measurements between the right and left sides of the mandible in both sexes. The mean Rt S-L, Rt I-L, and Rt MF-MS were significantly higher in males than females in both age groups. The receiver operating characteristic curve analysis identified the Rt I-L as the best valid and accurate one (area under the curve was 0.950 and accuracy was 87.2\%) for sex determination. A combination of Rt S-L, Rt I-L, and Rt MF-MS for sex prediction identified males correctly in $95.3 \%$ and females in $94.4 \%$ of the studied cases with overall predictive accuracy of $94.9 \%$. It could be concluded that a combination of SL, I-L, and MF-MS has shown promising applications in sex determination among Egyptians. For more population specific standards and accurate sex identification, further research on a greater number of cases including more age groups is recommended.
\end{abstract}

Keywords: forensic anthropology; sex determination; mental foramen; panoramic radiographs; Egyptian population.

\section{INTRODUCTION}

Sex determination is a crucial issue and usually the first step in the process of identification in forensic case works. This is primarily required in cases of crime investigations, and in identification of missing persons (Ramakrishnan et al., 2015). However, this remains very challenging task due to wide range of skeletal characteristics (Chandra et al., 2013). So, developing multiple reliable methods for estimating these aspects increase the chance of accurate identification (Meeusen et al., 2015).

The skull including the mandible is next to the pelvis in determination of sex. Additionally, the mandible is the hardest bone in the body and remains well preserved longer than any other 
bone (Hu et al., 2006). The mental foramen is an important reference mark located on anterolateral aspect of the body of the mandible (Lipski et al., 2013).

Panoramic radiography is a widely used tool that allows visualization of the mandible with accurate location of the mental foramen in both horizontal and vertical dimensions (Al-Shayyab et al., 2015). This technique is characterized by being readily available and cheap. Moreover, the presence of digital panoramic radiography that increased the quality of images favored its use in forensic anthropology. Another advantage of digital panoramic radiography is the availability of portable imaging units, so it is easily performed in certain circumstances like in mass disaster (Sahni et al., 2015).

It is well known that sexual dimorphism varies among different populations due to distinct anatomic features. So, there is a need to assess each population specific standards (Zorba et al., 2011). Although osteometric studies have attempted to determine the influence of sex on the horizontal and vertical measurements related to the mental foramen in different races (Thomas et al., 2004; Apinhasmit et al., 2006 ; Amorim et al., 2008;Afkhami et al., 2013; Chandra et al., 2013). Yet, according to the best of our recent knowledge no data are available about mental foramen related mandibular measurements among Egyptians. Therefore, the aim of this study was to determine the validity of some radiographic horizontal and vertical mandibular measurements related to the mental foramen in sex determination in a sample of Egyptian population.

\section{SUBJECTS \& METHODS}

This study was done on four hundred and thirty digital panoramic radiographs of Egyptian patients who had undergone a dental panoramic radiograph examination as a part of their treatment. This was carried out at the oral medicine, periodontology, diagnosis and oral radiology department, Faculty of Dentistry in Cairo, El Azhar University. Written informed consent was obtained from each patient involved in the study before the use of his/ her personal or imaging data.

Panoramic radiographs of either male or female patients aged 20 years or more with good quality regarding patient position, head alignment, film density, contrast and clearly visible lower border of the mandible, and both mental foramina were included. Images that did not achieve these predetermined requirements were not included in the study. Patients with any systemic disease that might affect bone metabolism, special dental diseases such as dysplasia of enamel or dentine and/or patients with history of dental surgery were excluded from the study.

All panoramic images were taken using the same digital panoramic machine (Planmeca, Proline EC, and Finland). Measurements related to the mental foramen were taken digitally using the Kodak dental imaging software. This was performed by the same observer on each radiograph.

Six measurements (in millimeters) were taken on each radiograph; two vertical measurements included the distance from superior border of the mental foramen to the lower border of the mandible (S-L), and from the inferior border of the mental foramen to the lower border of the mandible (IL). A horizontal measurement from the 
medial margin of the mental foramen to the mandibular symphisis (MF -MS) on both right (Rt) and left (Lt) sides of the mandible as illustrated in fig. (1).

Age and sex were recorded from the panoramic radiograph of each patient. The recruited sample included 215 male and 215 female aged from 20-68 years old. Because the vertical and horizontal position of the mental foramen is influenced by mandibular growth (Parnami et al., 2015), the studied cases were divided into two age groups; group 1 (from 20-50 years) and group 2 (more than 50 years).

\section{- Statistical Analysis}

Data were represented as mean and standard deviation. They were tested for normality of their distribution using Shapiro-Wilk test. Comparison between means of the studied measurements among both sexes in each age group and between both mandibular sides was done by Student's t-test and paired t- test respectively. The receiver operating characteristic (ROC) curves were constructed to test the validity and accuracy of the studied measurements in sex discrimination. Additionally, binary logistic regression was done to determine the accuracy of sex prediction using a combination of the studied measurements. All analyses were done by using SPSS v. 20. Pvalue was considered significant if below 0.05 .

\section{RESULTS}

Table (1) shows distribution of the measurements from the upper border of the mental foramen to the base of the mandible (S-L), from the lower border of the mental foramen to the base of the mandible (I-L), and from the medial margin of the mental foramen to the mandibular symphisis (MF-MS) according to the sex on both right and left mandibular sides. Paired comparison of these measurements between the right and left sides in both males and females revealed nonsignificant differences ( $p>0.05)$.

The right side measurements were studied for their validity in sex determination. Table (2) demonstrates that the mean Rt S-L, Rt I-L, and Rt MF-MS measurements were significantly higher in males than females in the age group 20-50 years. In the older age group ( $>50$ years), sex had also statistically significant influence on the analyzed measurements $(\mathrm{p}<0.001)$ with the higher values had been also verified in males (tables 3 ).

Table (4) and fig. (2) show the results of ROC curve analysis for sex discrimination using the Rt S-L, Rt I-L, and Rt MF-MS measurements. They were significantly valid in discriminating males from females $(\mathrm{p}<$ 0.001). Perfect sex discrimination was observed for the Rt I-L followed by Rt S-L and Rt MF-MS (area under the curves were $0.950,0.934$, and 0.927 respectively) with accuracy of $87.2 \%$, $85.6 \%$, and $87.2 \%$ respectively. The optimal cut-off values for sex prediction were identified; the Rt I-L length of $10.85 \mathrm{~mm}$ or higher was predictive of male sex with $89.5 \%$ sensitivity and $86.5 \%$ specificity.

The accuracy of sex prediction using a combination of Rt S-L, Rt I-L, and Rt MF-MS measurements was analyzed by a logistic regression model; it was significant ( $\mathrm{x}^{2}=$ $464.831, p<0.001$ ), accuracy of male and female prediction was $95.3 \%$ and $94.4 \%$ of the studied cases respectively with overall accuracy of sex prediction was $94.9 \%$ as shown in table (5). 
Table (1): Distribution of the studied measurements (S-L, I-L, and MF-MS) according to sex with paired comparison between the right and left sides of the mandible $(\mathrm{N}=430)$

\begin{tabular}{|c|c|c|c|c|c|c|}
\hline \multirow{2}{*}{ Measurements } & & & \multirow{2}{*}{$\begin{array}{l}\text { Right side } \\
\text { Mean } \pm \text { SD } \\
(\mathrm{mm})\end{array}$} & \multirow{2}{*}{$\begin{array}{c}\text { Left side } \\
\text { Mean } \pm \text { SD } \\
(\mathbf{m m})\end{array}$} & \multicolumn{2}{|c|}{ Paired T- test } \\
\hline & & & & & $\mathbf{t}$ & $P$ value \\
\hline \multirow{2}{*}{ S-L } & Males & $\mathrm{N}=215$ & $16.76 \pm 1.99$ & $16.78 \pm 1.95$ & -.894 & 0.372 \\
\hline & Females & $\mathrm{N}=215$ & $12.51 \pm 1.73$ & $12.52 \pm 1.73$ & 1.097 & 0.274 \\
\hline \multirow{2}{*}{ I-L } & Males & $\mathrm{N}=215$ & $12.63 \pm 1.31$ & $12.64 \pm 1.32$ & .761 & 0.447 \\
\hline & Females & $\mathrm{N}=215$ & $9.25 \pm 1.43$ & $9.25 \pm 1.43$ & -.995 & 0.318 \\
\hline \multirow{2}{*}{ MF-MS } & Males & $\mathrm{N}=215$ & $29.62 \pm 1.55$ & $29.63 \pm 1.55$ & -.256 & 0.799 \\
\hline & Females & $\mathrm{N}=215$ & $26.51 \pm 2.46$ & $26.52 \pm 2.43$ & 0.092 & 0.927 \\
\hline
\end{tabular}

$\mathrm{N}$; number, SD; standard deviation

Table (2): Comparison of the Rt side mandibular measurements between males and females aged $20-50$ years $(\mathrm{N}=330)$

\begin{tabular}{|c|c|c|c|c|c|c|}
\hline \multirow{2}{*}{$\begin{array}{c}\text { Group } 1 \\
(20-50 \text { years })\end{array}$} & \multirow{2}{*}{ Sex } & \multirow{2}{*}{$\mathbf{N}$} & \multirow{2}{*}{$\begin{array}{l}\text { Mean } \\
(\mathrm{mm})\end{array}$} & \multirow{2}{*}{$\begin{array}{c}\text { SD } \\
(\mathbf{m m})\end{array}$} & \multicolumn{2}{|c|}{ Student's T -test } \\
\hline & & & & & $\mathbf{T}$ & P value \\
\hline \multirow{2}{*}{ Rt S-L } & Male & 165 & 16.68 & 2.01 & \multirow{2}{*}{18.31} & \multirow{2}{*}{$<0.001 *$} \\
\hline & Female & 165 & 12.79 & 1.84 & & \\
\hline \multirow{2}{*}{ Rt I-L } & Male & 165 & 12.52 & 1.33 & \multirow{2}{*}{21.58} & \multirow{2}{*}{$<0.001 *$} \\
\hline & Female & 165 & 9.18 & 1.47 & & \\
\hline \multirow{2}{*}{ Rt MF-MS } & Male & 165 & 29.23 & .68 & \multirow[b]{2}{*}{16.075} & \multirow{2}{*}{$<0.001 *$} \\
\hline & Female & 165 & 26.40 & 2.15 & & \\
\hline
\end{tabular}

*Significant at $\mathrm{P}$ value $<\mathbf{0 . 0 5}, \mathrm{N}$; number, $\mathrm{SD}$; standard deviation

Table (3): Comparison of the Rt side mandibular measurements between males and females aged more than 50 years $(\mathrm{N}=100)$

\begin{tabular}{|c|c|c|c|c|c|c|}
\hline \multirow{2}{*}{$\begin{array}{c}\text { Group } 2 \\
\text { (more than } \\
50 \text { years) }\end{array}$} & \multirow{2}{*}{ Sex } & \multirow{2}{*}{$\mathbf{N}$} & \multirow{2}{*}{$\begin{array}{c}\text { Mea } \\
\mathbf{n} \\
(\mathbf{m m})\end{array}$} & \multirow{2}{*}{$\begin{array}{c}\text { SD } \\
(\mathbf{m m})\end{array}$} & \multicolumn{2}{|c|}{ Student's T-test } \\
\hline & & & & & $\mathbf{t}$ & $P$ value \\
\hline \multirow{2}{*}{ Rt S-L } & Male & 50 & 17.03 & 1.9 & \multirow{2}{*}{18.38} & \multirow{2}{*}{$<0.001 *$} \\
\hline & Female & 50 & 11.61 & 0.75 & & \\
\hline \multirow{2}{*}{ Rt I-L } & Male & 50 & 13.01 & 1.48 & \multirow{2}{*}{12.67} & \multirow{2}{*}{$<0.001 *$} \\
\hline & Female & 50 & 9.50 & 1.27 & & \\
\hline \multirow{2}{*}{ Rt MF-MS } & Male & 50 & 30.90 & 2.60 & \multirow{2}{*}{6.78} & \multirow{2}{*}{$<0.001 *$} \\
\hline & Female & 50 & 26.68 & 3.31 & & \\
\hline
\end{tabular}

*Significant at $\mathrm{P}$ value $<\mathbf{0 . 0 5}, \mathrm{N}$; number, $\mathrm{SD}$; standard deviation 
Table (4): The results of receiver operating characteristic (ROC) curves analysis for sex discrimination using the Rt side mandibular measurements $(\mathrm{N}=430)$

\begin{tabular}{|c|c|c|c|c|c|c|}
\hline & $\begin{array}{c}\text { Cut-off } \\
\text { value }(\mathbf{m m})\end{array}$ & $\begin{array}{c}\text { Sensitivity } \\
\mathbf{\%}\end{array}$ & $\begin{array}{c}\text { Specificity } \\
\mathbf{\%}\end{array}$ & $\begin{array}{c}\text { Accuracy } \\
\mathbf{\%}\end{array}$ & $\begin{array}{c}\text { ROC- } \\
\text { AUC }\end{array}$ & P value \\
\hline Rt S-L & $\geq 14.1$ & $85.5 \%$ & $81 \%$ & $85.6 \%$ & .934 & $<0.001 *$ \\
\hline Rt I-L & $\geq 10.85$ & $89.5 \%$ & $86.5 \%$ & $87.2 \%$ & 0.950 & $<0.001 *$ \\
\hline Rt MF-SM & $\geq 28.85$ & $86 \%$ & $81.5 \%$ & $87.1 \%$ & .927 & $<0.001 *$ \\
\hline
\end{tabular}

*Significant at $P$ value $<0.05, \mathrm{AUC}$; area under the curve.

Table (5): Sex prediction using binary logistic regression analysis of a combination of Rt S-L, Rt I-L, and Rt MF-MS mandibular measurements

\begin{tabular}{|c|c|c|c|c|}
\hline \multicolumn{2}{|c|}{ Observed } & \multicolumn{3}{c|}{ Predicted } \\
\cline { 3 - 5 } \multicolumn{2}{|c|}{} & \multicolumn{2}{|c|}{ Sex } & Correct ( true positive) \\
\cline { 3 - 5 } & Male & Female & \\
\hline \multirow{2}{*}{ Sex } & Male $: 215$ & 205 & 10 & 95.3 \\
\cline { 2 - 5 } & Female: 215 & 12 & 203 & 94.4 \\
\hline \multicolumn{2}{|c|}{ Overall accuracy (\%) } & & & 94.9 \\
\hline
\end{tabular}

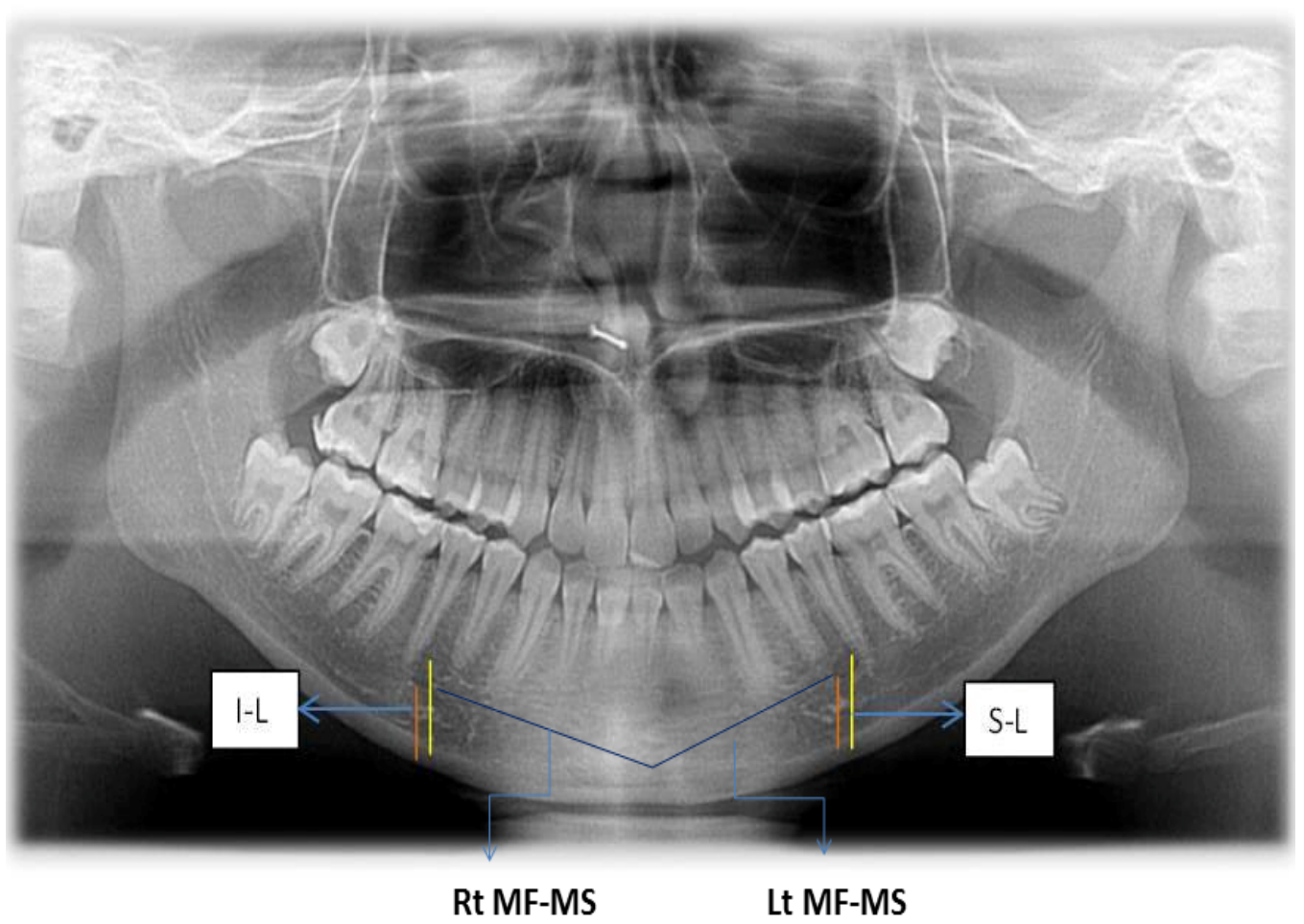

Figure.(1): Panoramic radiograph showing mental foramen and measurements related to it on both Rt and Lt mandibular sides; S-L (from the superior border of the mental foramen to the lower border of the mandible), I-L (from the inferior border of the mental foramen to the lower border of the mandible) and MF-MS (from the medial margin of the mental foramen to the mandibular symphesis). 


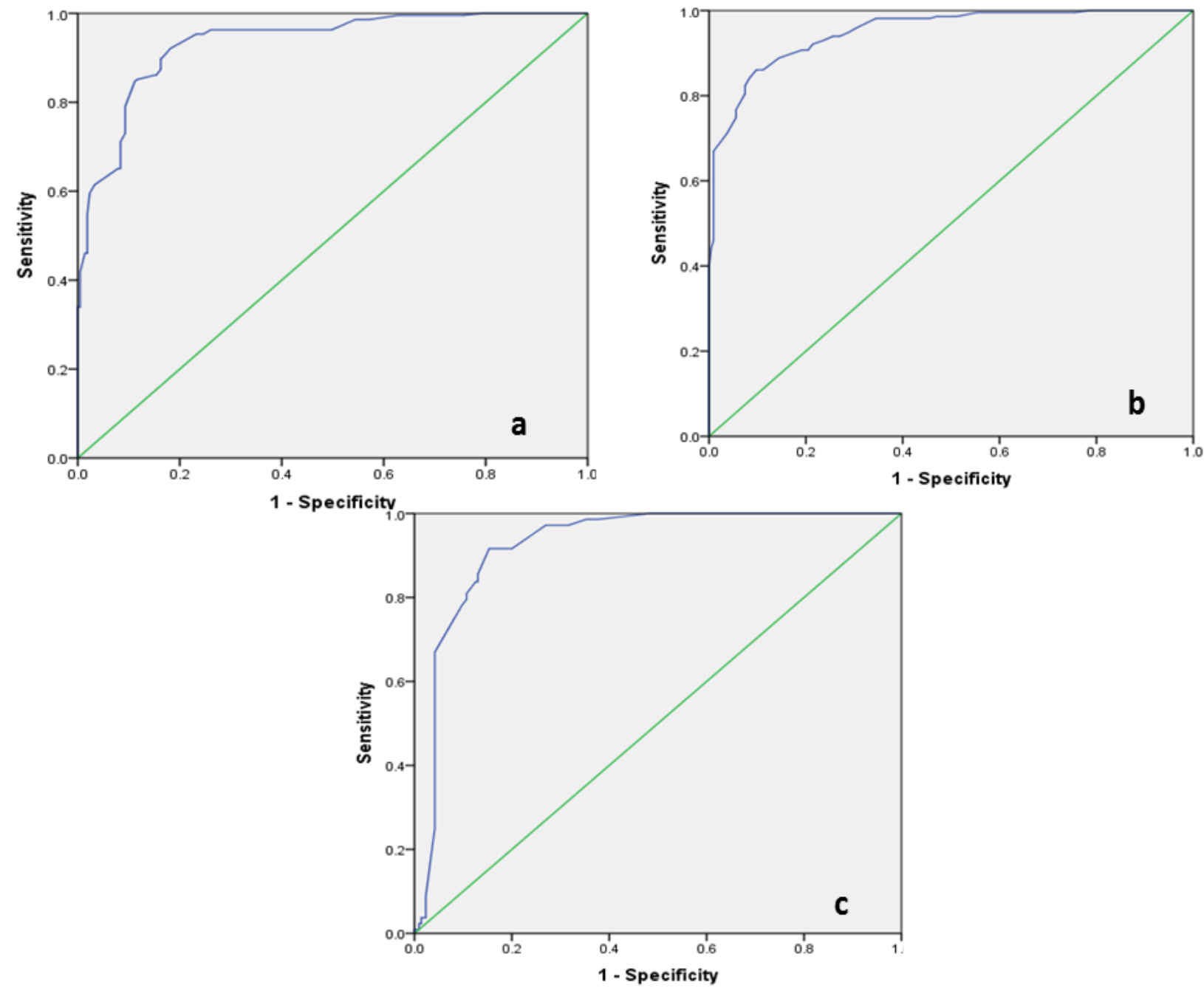

Figure (2): Receiver operating characteristic curves showing the best sensitivity and specificity for Rt S-L (a), Rt I-L (b), and Rt MF-MS (c) in sex prediction.

\section{DISCUSSION}

In the current study, it was evident that S-L, I-L, and MF-MS on either Rt or Lt mandibular sides showed significantly higher mean values in males than females. The ROC curve analysis identified the Rt I-L measurement as the best valid and accurate one for sex discrimination. A combination of Rt S-L, Rt I-L, and Rt MF-MS measurements for sex prediction identified males correctly in $95.3 \%$ and females in $94.4 \%$ of the studied cases with overall accuracy of sex determination of $94.9 \%$.

In this study, the mean values of S$\mathrm{L}$ and I-L in both sexes were smaller than reported in similar previous Indian studies (Sankar et al., 2011; Thakur et al. 2014; Naroor et al. 2015) whereas, the mean distance of I-L reported in in this study was greater than that measured in Iraqi population Rashid and Ali (2011) and Brazilian population (Saito et al., 2015). The mean length of MF-MS measurement obtained in this study was consistent with that reported for Brazilian, black Africans, Chinese, and Thai subjects (Amorim et al., 2008; Souaga et al. 2004; Apinhasmit et al., 2006). In contrast, Indian studies on dry mandibles revealed lower mean values for MF-MS measurements on both Rt 
and Lt mandibular sides (Siddiqui et al., 2011; Rai et al., 2014). Older osteometric studies on white British, Koreans, white and black Americans also revealed lower mean values for MF-MS (Chung et al., 1995; Cutright et al., 2003). The observed racial diversity advocate the importance of studies in different populations.

The comparison of the studied measurements between the right and left mandibular sides in both males and females revealed non-significant differences. This finding was in agreement with those reported by Amorim et al. (2008) and Rashid and Ali (2011). Previous studies demonstrated that the mental foramens had almost symmetrical position on both sides (Junior et al., 2009; Afkhami et al., 2013). This suggests that the presence of half or even part of the mandible with mental foramen and intact lower border can be used for sex determination.

The present study demonstrated that, the mean values of $\mathrm{S}$-L were significantly higher in males than females in both age groups. Previous studies on other races reported similar results; Mahima et al. (2009) and Chandra et al. (2013) in India, Afkhami et al. (2013) in Tehran, Iran, Catovie et al. (2002) in Croatia and Thomas et al. (2004) in Australia.

The current work also revealed that, the mean values of I-L showed sexual dimorphism with higher values in males in all age groups. This finding was in agreement with Amorim et al. (2008), Rashid and Ali, (2011), Afkhami et al. (2013), and Saito et al.( 2015) who demonstrated differences in I-L among both sexes in Brazilian, Iraqi, north Indian, and São Leopoldo Mandic subjects respectively. In contrast, only one Croatian study didn't show sexual dimorphism in I-L measurement (Vodanovic et al., 2006).

Sex had also significantly affected the values of MF-MS with higher means in males in both young adults and older ages. Sexual dimorphism in this measurement was also revealed by Apinhasmit et al. (2006) and Amorim et al. (2008) in Thai and Brazilian subjects. In contrast, Chung et al. (1995) and Cutright et al. (2003) demonstrated non-significant differences in the distance from the mental foramen to the mandibular symphesis among both sexes. These observed differences may be attributed to different methodology such as measurements on dry skull, photographs or radiographs Chung et al. (1995).

In this study, the significant influence of sex on the analyzed measurements with the higher values observed in males may be attributed to the higher rate of bone growth of craniofacial dimensions in males under effects of sex hormones (Singal and Sharma, 2016). In addition, considerable sex differences in the relative position of the mental foramen in adult skulls and isolated mandibles have been shown by Juodzbalys et al. (2010).

In this work, Rt S-L, Rt I-L, and Rt MF-MS were significantly valid in discriminating males from females as demonstrated by ROC curve analysis for sex prediction. Additionally, the $\mathrm{Rt}$ I-L was detected as the best predictor of sex followed by Rt S-L, then Rt MFMS (area under the curves were 0.950, 0.934, and 0.927respectively). The Rt I-L length of $10.85 \mathrm{~mm}$ or higher was predictive of male sex with $89.5 \%$ 
sensitivity while at a cut off of 14.1 $\mathrm{mm}$ or higher, the Rt S-L predicted male sex with $85.5 \%$ sensitivity.

Previous studies on sex determination from measurements obtained from panoramic radiographs of the mental foramen revealed supportive results. In north Indian population, Chandra et al. (2013) suggested that Rt I-L above $11.99 \mathrm{~mm}$ and Rt S-L above $17.036 \mathrm{~mm}$ were predictive of male sex in $95 \%$ of the cases. Higher accuracy was reported by Mahima et al. (2009) who stated that distances above $1.7 \mathrm{~cm}$ for S-L and $1.48 \mathrm{~cm}$ for I-L were predictive of male sex in $99 \%$ of a south Indian population. The work conducted on Iraqi population by Rashid and Ali, (2011) revealed a significant but lower power of sex discrimination of I-L on either the Rt or the Lt sides $(p<0.001$ and area under the ROC curve = 0.635). They reported that I-L $\geq$ $9.67 \mathrm{~mm}$ predicted male sex with $70.2 \%$ sensitivity and $60.8 \%$ accuracy.

\section{CONCLUSION}

This study has given a preparatory assessment to some measurements related to the mental foramen intended for sex determination from the mandible among Egyptians. A combination of S-L, I-L, and MF-MS mandibular measurements has shown promising applications in sex determination (overall accuracy of sex prediction was 94.9\%). Further research on a greater number of cases including more age groups and different governorates in Egypt to get results which can be utilized as population- specific standards and to identify sex accurately is recommended.

\section{REFERENCES:}

Afkhami F, Haraji A, Boostani HR (2013): Radiographic localization of the mental foramen and mandibular canal. J Dent (Tehran); 10(5): 436.

Al-Shayyab MH, Alsoleihat F, DarOdeh NS, et al. (2015): The Mental Foramen I: Radiographic Study of the Anterior Posterior Position and Shape in Iraqi Population. Int. J. Morphol.; 33(1):149-157.

Amorim MM, Prado FB, Borini CB, et al. (2008): The mental foramen in dentate and edentulous Brazilian's mandible. Int. J. Morphol. ; 26(4):981-987.

Apinhasmit W, Chompoopong S, Methathrathipm D, et al. (2006): Supraorbital Notch/ Foramen, Infraorbital Foramen and Mental Foramen in Thais: anthropometric measurements and surgical relevance. J Med Assoc Thai; 89(5), 675-82.

Catovie A, Bergman V, Seifert D, et al. (2002): Influence of sex, age and presence of functional units on optical density and bone height of the mandible in the elderly. Acta Stomatol Croat; 6:327-328.

Chandra A, Singh A, Badni M, et al. (2013): Determination of sex by radiographic analysis of mental foramen in North Indian population. J Forensic Dent Sci; 5(1): 52-55.

Chung MS, Kim HJ, Kang HS et al. (1995): Locational relationship of the supraorbital notch or foramen and infraorbital and mental foramina in Koreans. Acta Anat. (Basel); 154:162.

Cutright B, Quillopa N, Schubert W (2003): An Anthropometric 
Analysis of the Key Foramina for Maxillofacial Surgery. J. Oral Maxillofac. Surg.; 61:354- 7.

Hu KS, Koh KS, Han SH, et al. (2006): Sex determination using non metric characteristics of the mandible in Koreans. J Forensic Sci; 51:1376-82.

Junior OEM, Araujo ALD, Da Silva CMF, et al. (2009): Morphological and morphometric study of the mental foramen on the M-CP-18 jiachenjiang point. Int $\mathrm{J}$ Morphol; 27(1):231-8.

Juodzbalys G, Wang HL, Sabalys G (2010): Anatomy of Mandibular vital structures. Part II: Mandibular Incisive Canal, Mental Foramen and associated Neurovascular Bundles in Relation with Dental Implantology; JOMR; 1(1): e3.

Lipski M, Tomaszewska IM, Lipska W, et al. (2013): The mandible and its foramen: anatomy, anthropology, embryology and resulting clinical implications. Folia Morphol; 72(4):285-92.

Mahima VG (2009): Mental foramen for gender determination: A panoramic radiographic study. Medico-Legal Update; 9:33-5.

Meeusen RA, Christensen AM, Hefner J T (2015): The Use of Femoral Neck Axis Length to Estimate Sex and Ancestry. J Forensic Sci; 60(5): 1300-1304.

Naroor N, Shenai P, Chatra L, et al. (2015): Gender determination using the mental foramen. J Cranio Max Dis; 4 (2):144-147.

Parnami P, Gupta D, Arora V, et al. (2015): Assessment of the Horizontal and Vertical Position of Mental Foramen in Indian Population in Terms of Age and Sex in Dentate Subjects by
Panoramic Radiographs: A Retrospective Study with Review of Literature. The open dentistry journal; 9: 297.

Rai R, Shrestha S, Jha S (2014): Mental foramen: A morphological and morphometrical study. Int $\mathrm{J}$ Health Biomed Res; 2: 144-150.

Ramakrishnan K, Sharma S, Sreeja C, et al. (2015): Sex determination in forensic odontology: A review. J Pharm Bioallied Sci; 7(2): S398S402.

Rashid SA and Ali J (2011): Sex determination using linear measurements related to the mental and mandibular foramina vertical positions on digital panoramic images. J Bagh College Dentistry; 23:59-64.

Sahni P, Patel RJ, Jaydeva HM, et al. (2015): Gender determination by pantomographic (OPG) analysis of mental foramen in north Gujarat population- A retrospective study. Med. Res. Chron.; 2 :( 5) 701-706.

Saito K, Araújo NSD, Saito MT, et al. (2015): Analysis of the mental foramen using cone beam computerized tomography. Revista de Odontologia da UNESP; 44(4):226-231.

Sankar DK, Bhanu SP, Susan PJ (2011): Morphometrical and morphological study of mental foramen in dry dentulous mandibles of South Andhra population of India. Indian J Dent Res; 22(4):542-6.

Siddiqui AU, Daimi SR, Mishra PP, et al. (2011): Morphological and morphometric analysis of mental foramen utilizing various assessment parameters in dry human mandibles. Int $\mathbf{J}$ Stud Res; 1(1): 19-22. 
Singal $K$ and Sharma $S$ (2016):

Gender Determination by Mental Foramen Using Linear Measurements on Radiographs: A Study in Haryana Population. Ind J Forensic Med Toxic; 10(1): 44-49.

Thakur M, Reddy K, Sivaranjani Y, et al. (2014): Gender Determination by Mental Foramen and Height of the Body of the Mandible in Dentulous Patients A Radiographic Study. J Indian Acad Forensic Med; 36:13-18.

Thomas CJ, Madsen D, Whittle C (2004): A radiologic survey of the edentulous mandible relevant to forensic dentistry. Leb J Dent Med; 3:15-20.

Vodanovic M, Dumancic J, Demo Z, et al. (2006): Determination of sex by discriminant functional analysis of mandibles from two Croatian archeological sites. Acta Stomatol Croat; 40:263-77.

Zorba E, Moraitis K, Manolis SK (2011): Sexual dimorphism in permanent teeth of Modern Greeks, Forensic Sci Int; 210:74-81. 


\section{الملخص العربيى}

\section{إزدواج الثكل الجنسي للقك السفلي في عينة من المصريين: دراسة باستخدام

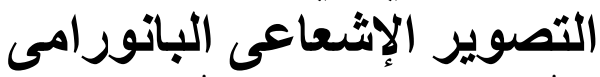

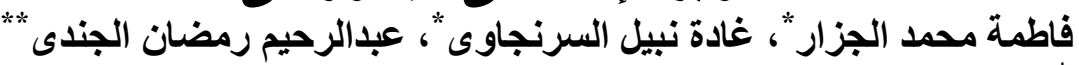

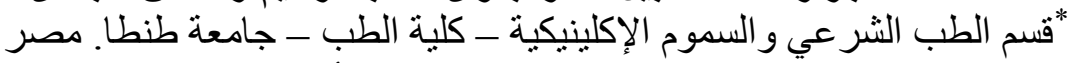

**قم طب الفم و امر اض اللثه و التثخيص و اثنعة الفم- كلية طب الأسنان بالقاهرة بنين- جامعة الأزهر ـ مصر

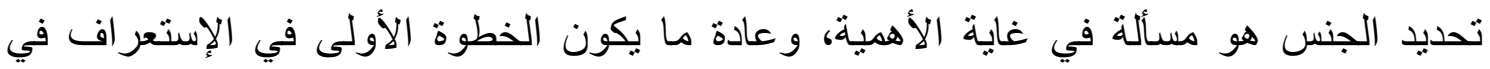

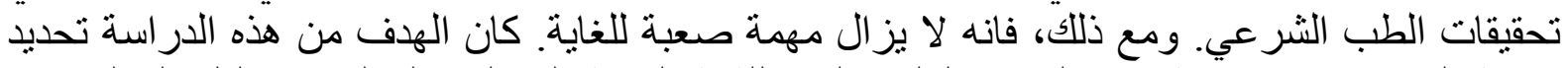

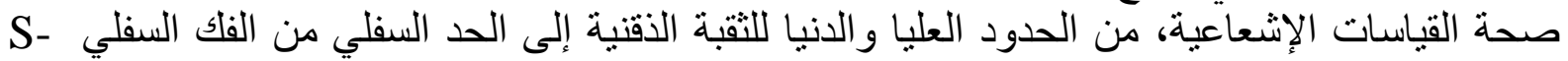

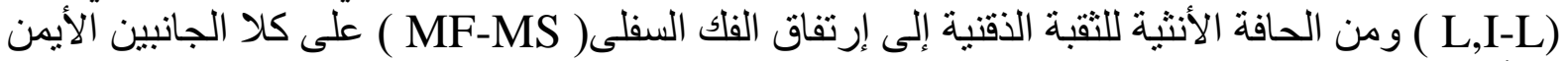

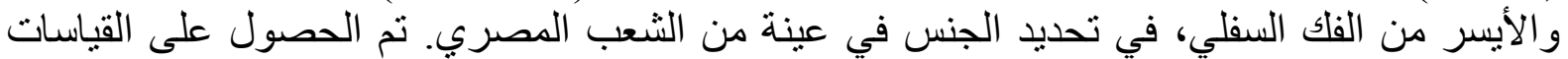

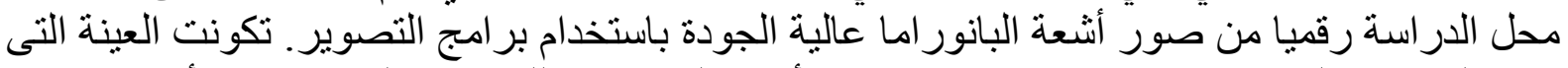

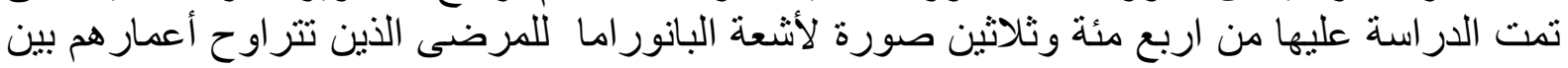

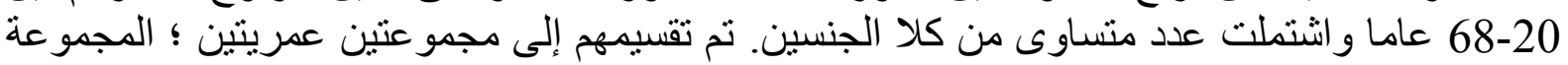

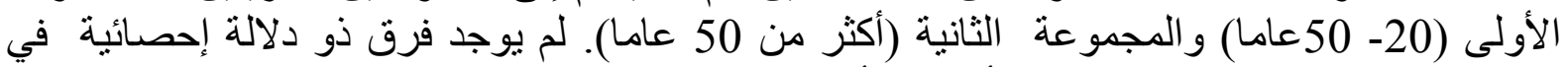

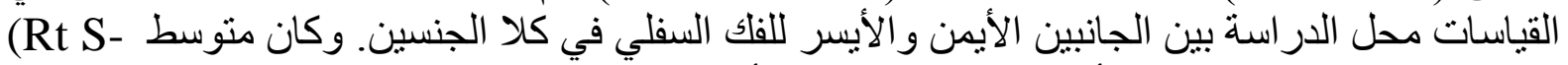
L, Rt I-L, Rt MF-MS)

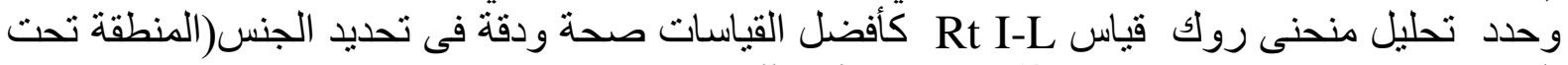

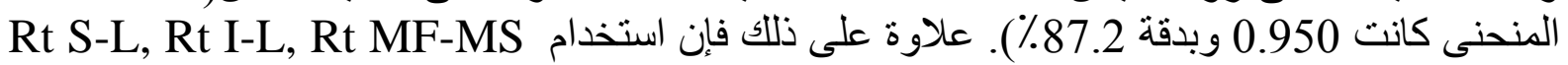

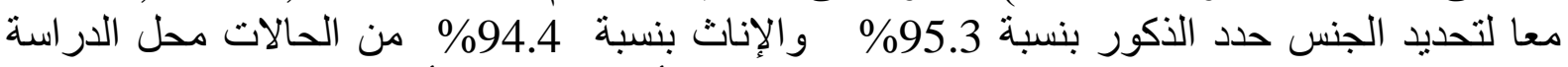

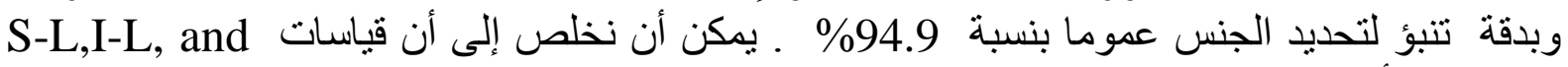

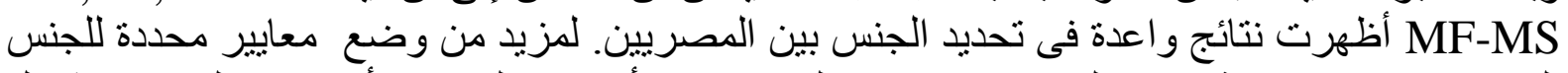

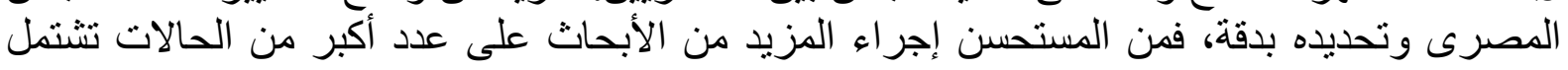

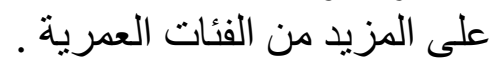

